\title{
Mri Evaluation Of Shoulder Joint: Normal Anatomy \& Pathological Finding A Pictorial Essay And Review
}

\author{
Hema Chaudhary ${ }^{1}$, Sangeeta Aneja ${ }^{2}$ \\ ${ }^{1}$ Resident, ${ }^{2}$ Professor \\ ${ }^{1,2}$ Department of Radiodiagnosis, L.L.R.M Medical College, Meerut
}

\begin{abstract}
In our study we evaluate MRI as an excellent soft tissue contrast and allows for multiplanar imaging in anatomic planes. Because of these advantages MRI has become the study of choice for imaging of shoulder pathology. It allows high-resolution imaging of all anatomic structures including the Rotator cuff tendons and muscles, glenoid, humeral head, articular cartilage, acromion, labrum, biceps tendon and the glenohumeral ligaments in multiple orthogonal planes. The aim of this review is to update orthopaedic surgeons on the technical aspects of performing magnetic resonance imaging of the shoulder. In addition, this report will define the normal anatomy of the shoulder as demonstrated by magnetic resonance imaging and review the spectrum of disease detectable with this technique.
\end{abstract}

Keywords : Articular cartilage, Capsule, Humeral head, Labrum, Glenoid, Glenohumeral ligaments Magnetic resonance imaging, Rotator cuff tendons and muscles,.

\section{Introduction}

Pain around the shoulder joint with or without reduced range of motion are commonly referred to the radiologist for evaluation. Clinical examination and plain radiographic assessment help in providing proper choice of subsequent investigation modality. MRI because of its excellent soft tissue contrast, imaging capability in any desired plane \& non ionising and non invasive nature is an ideal modality of investigation. It has replaced all other tests and considered as screening modality of choice in evaluation of shoulder problems $[10,11]$.

\section{NORMAL ANATOMY}

Shoulder joint is a ball and socket type joint formed by articulation between head of humerus and glenoid of scapula. Structurally it is a weak joint due to disparity of articulating surface area between small and shallow glenoid cavity in comparison to head of humerus. However this arrangement provides the glenohumeral joint with greater range of movements of any articulation in human body $[5,6,45]$. Stability to this unstable joint is provided by following structures: 1)Musculotendinous cuff of shoulder 2)Coraco-acromion arch consisting of acromion, coracoacromian ligament, coracoids process, and coraco-acromio-clavicular joint. 3)Glenoid labrum along with capsule and glenohumeral ligament.[53,54]

The joint capsule is loose and allows free movements. It is least supported inferiorly where dislocations are common. The capsule is reinforced anteriorly and inferiorly by several thickenings known as inferior glenohumeral ligament (IGHL),middle glenohumeral ligament, smallest superior glenohumeral ligament. They all extend to anterior neck of humerus and stabilise the joint [5,6,45]. Glenoid labrum is a fibrocartilagenous ovoid rim attached to the margin of glenoid cavity. It is often deficient anteriosuperiorly. Its functions to deepen the glenoid cup \& is a site of capsule-ligamentous attachment.

\section{NORMAL MRI ANATOMY OF SHOULDER JOINT}

Axial Section: shows the cuff muscles as an intermediate signal intensity structures. Highest section shows supraspinatus muscle followed posteriorly by infraspinatus muscle $\&$ teres minor $\&$ its tendons. the tendon appears darker than muscle \& can be traced to greater tuberosity. Biceps tendon is seen anteriosuperiorly \& sabscapularis tendon anterior to the scapula at midsuperior head level. Bicipital groove is best seen on these sections lateral to lesser tuberosity. Anterior \& posterior labra are particularly are well seen on axial sections. The glenohumeral ligaments are low signal structures \& better seen in presence of fluid in the joint or on MR arthograms. The articular cartilage appear bright on T2 \& gradient images \&best evaluated in axial sections(Fig $1 \& 2)$. 

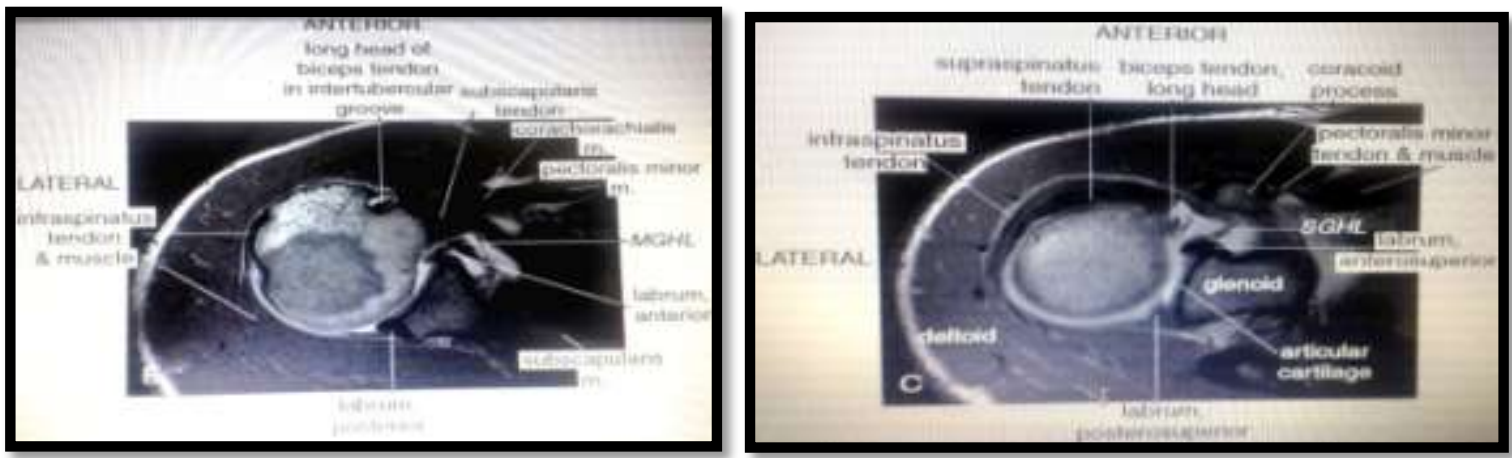

Figures 1 \& 2: Normal MRI anatomy on axial section

Coronal Sections: The rotator cuff tendon structures are best evaluated on oblique coronal sections. The mid to anterior section show the supraspinatus tendon [along with the acromioclavicular joint] the sections posterior to this show conjoint tendons of supraspinatus tendon \& infraspinatus tendon \& tendon minor. The tendons can be traced to greater tuberosity. The subacromian subdeltoid bursa appears as a thin bright line beneath the deltoid muscle on T1 /T2WI. The anterior sections also show supraspinatus tendon \& biceps tendon passing beneath it as well as coracohumeral, coracoacromian \& coracoclavicular ligaments. The superior labrum is best evaluated for injury in the coronal plane. Axillary pouch is seen medial and inferior to humeral head. (Fig $3 \& 4$ ).
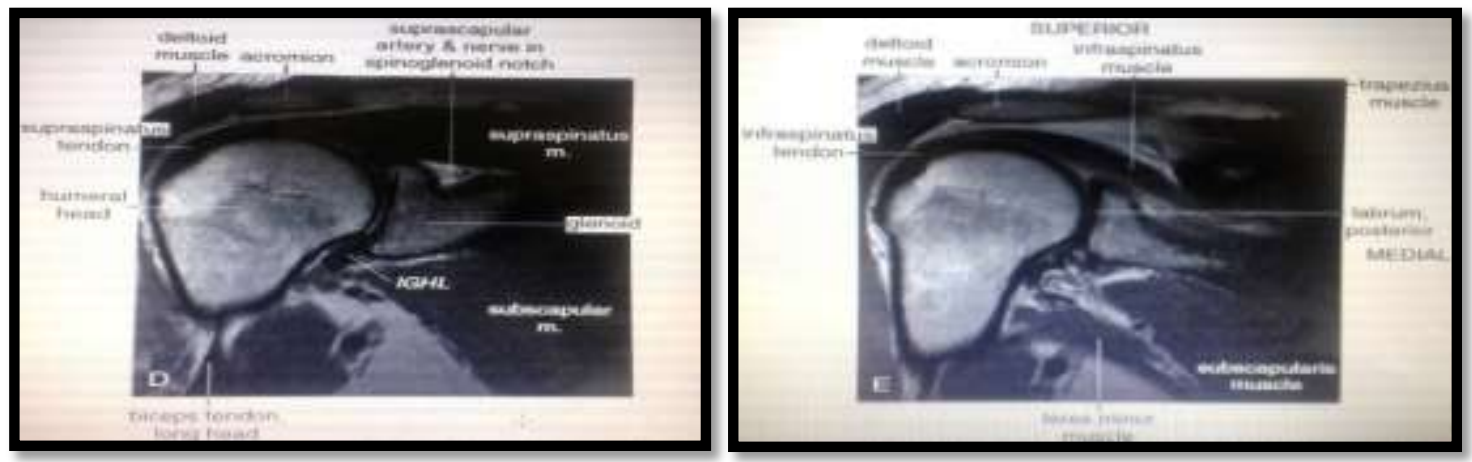

Figures 3 \& 4: Normal MRI anatomy on coronal section

Sagittal Section:These provide a cross-sectional view of all the muscles of the shoulder. Mid and lateral sagittal images show the supraspinatus tendon/infraspinatus tendon as a low signal structure between humeral head and acromion. The morphological abnormalities of acromion (which is anterior sloping) are best shown on these images. The long head of biceps can be seen passing anterioinferiorly between supraspinatus tendon and sabscapularis tendon through the rotator cuff interval. These superior glenohumeral ligament can be seen lying beneath the long head of biceps. The middle glenohumeral ligament anterior to medial humeral head and inferior glenohumeral ligament along with a thick inferior labrum along the inferior aspect of the glenoid cavity. (Fig 5\&6).
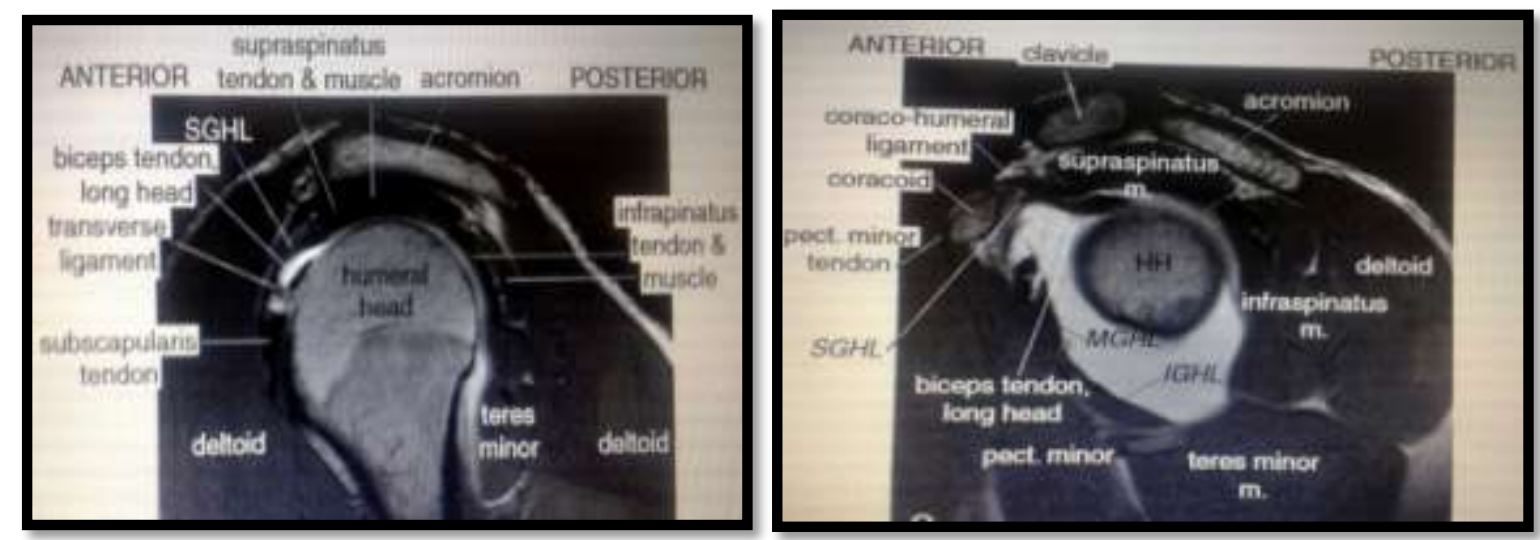

Figures 5 \& 6: Normal MRI anatomy on sagittal section 


\section{PATHOLOGY}

As regards to pathology, there are many but the three most important entities affecting the shoulder will be addressed here: A)Impingement, B) Rotator cuff ruptures, and C) Instability

Few other important pathology : Adhesive capsulitis , Biceps tendinopathy ,

\section{Impingement syndrome}

Primary impingement is due to narrow space between the humeral head and the coraco-acromial arch (superior impingement) or between humeral head and coracoid process (anterior impingement) [27,28,29]. In primary impingement all structures forming the coraco-acromial arch can cause the impingement. . Most frequently osteophytes arising from the acromion or thickening of coracoacromial ligament cause supraspinatus compression i.e. impingement. There are three different configurations of acromia [7]. Type 1 acromion is characterized by a flat undersurface. Type 2 acromion demonstrates a curved undersurface. . A type 3 acromion is rare and characterized by a convex undersurface \& most frequently associated with rotator cuff injury. Type II and III may predispose to superior impingement(Fig - $7 \& 8$ ). Also, os acromiale or hypertrophy of AC joint osteophytes can cause impingement. [19,20,45](Fig -9). Subcoracoid impingement occurs after fractures of coracoid or lesser tubercle.
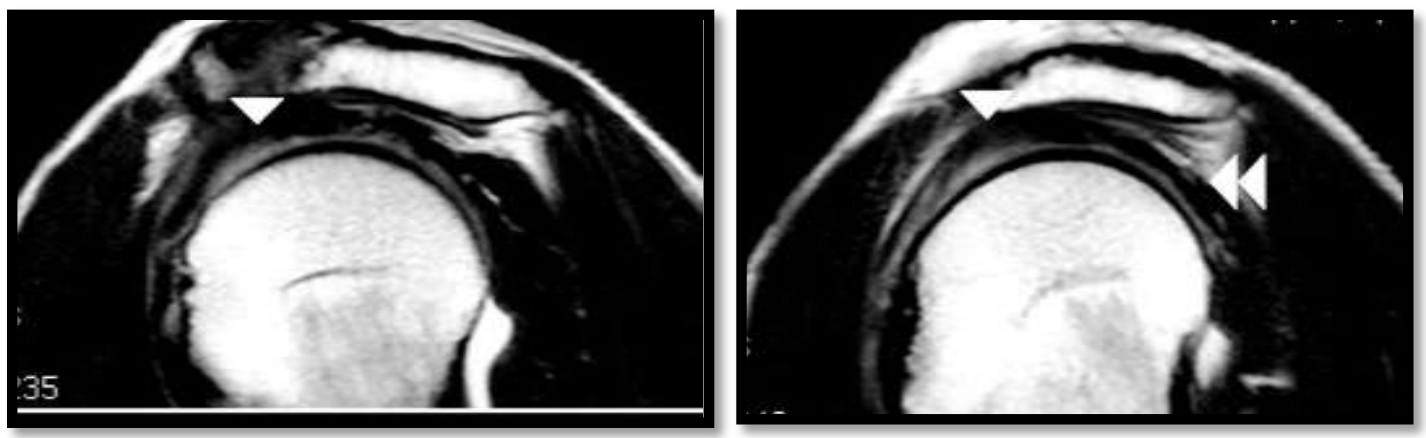

Figure 7\& 8 :Impingement in association with curved Acromion (Type II).

Figure 7- Sagittal slices show thickening and increased signal due to Tendinosis in ventral portion of supraspinatus tendon

Figure 8 - Distal portion shows normal thin combine supra / infraspinatus tendon .

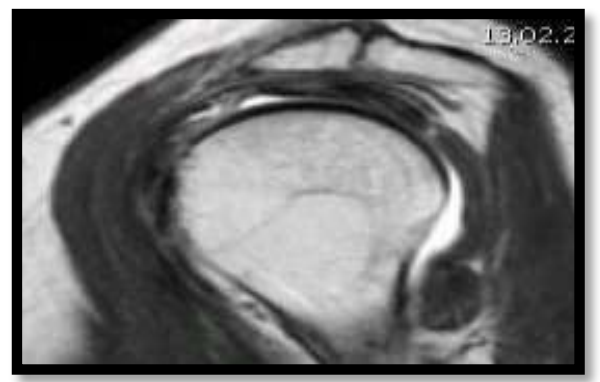

Figures 9 : Impingement in os acromiale. Sagittal T2W slice additionally shows a moderate sized partial tear of the anterior portion of the supraspinatus tendon with perifocal tendinosis

Secondary impingement is due to instability of the very mobile shoulder joint, leading to dynamic narrowing of the thoracic outlet. As mentioned, secondary extrinsic impingement occurs in cases of instability [21] . These patients are frequently athletes and their repetitive overhand activities as throwing may lead to posterosuperior glenoid impingement [49] and degeneration, as well as tearing of the articular fibres at the junction between the infraspinatus and supraspinatus tendons. The damage occurs during abduction and external rotation and is often associated with posterosuperior glenoid labral tears. Neer stages of impingement [18]] : 3 Stages :Stage I Reversible oedema, Stage II - Fibrosis and tendinosis, Stage III - Tears of cuff.

The MR pictures in impingement may be normal, or show thickening with increased signal replacing the normally low signal of a healthy tendon or may be a partial /complete tear of the tendon affected. 


\section{Rotator Cuff Rupture}

On MRI tears of the rotator cuff are visualized in all major planes as fluid fills the gaps in the tendon, be they superior, anterior or posterior. Tears most frequently occur in areas of tendinosis near the humeral attachment on the major[8,33]. Tendinosis creates increased signal in short TE MRI sequences and may be easier diagnosed if tendon also thickened. By its exposed location under the acromion, the supraspinatus tendon is most commonly involved in tendinosis. As regards to tears, full thickness tears are distinguished from partial tears, which can be very small or moderate sized These again can involve the bursal or the articular side, with articular sided tears more frequent $[3,22]$ (Fig 10, 11). Partial tears may also be located within the substance of the tendon, the so called "intrasubstance" tears (Fig 12).. Partial or complete full-thickness tears may coexist in different portions of cuff. Rent tears are anterior and are usually small. Full thickness tears are divided into small $(\leq 1 \mathrm{~cm})$, medium $(1-3 \mathrm{~cm})$, large $(3-5 \mathrm{~cm})$ or massive $(\geq 5 \mathrm{~cm})$ tears [16, 23] (Fig 13).. Massive tears, besides involving the supraspinatus tendon, usually also affect the infraspinatus tendon posteriorly and the rotator interval and subcapularis tendon anteriorly. In such tears there will be retraction of the tendon stumps and muscular atrophy. Also cranial migration of the head is usually seen already in plain x-ray views, as the cuff above the head is missing .Partial tears are graded into Grade I if less than one fourth of the tendon or $<3 \mathrm{~mm}$,

Grade II if less than one half $(3-6 \mathrm{~mm})$ and

Grade III if more than one half of the tendon $(>6 \mathrm{~mm})$ is involved

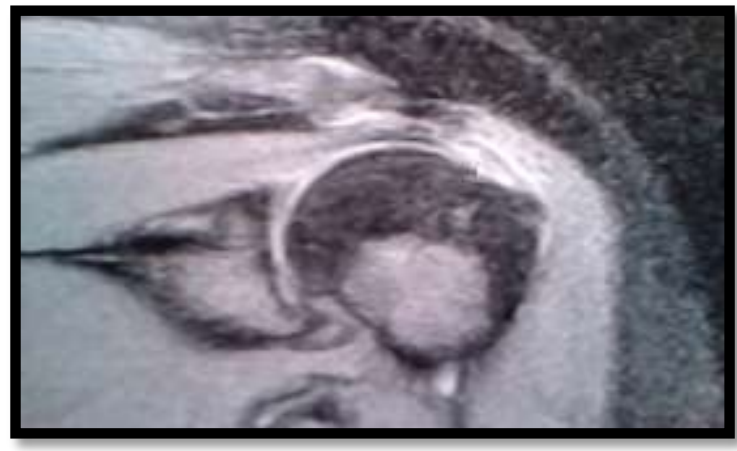

FIGURE 10: Coronal PD image shows Articular Surface partial tear

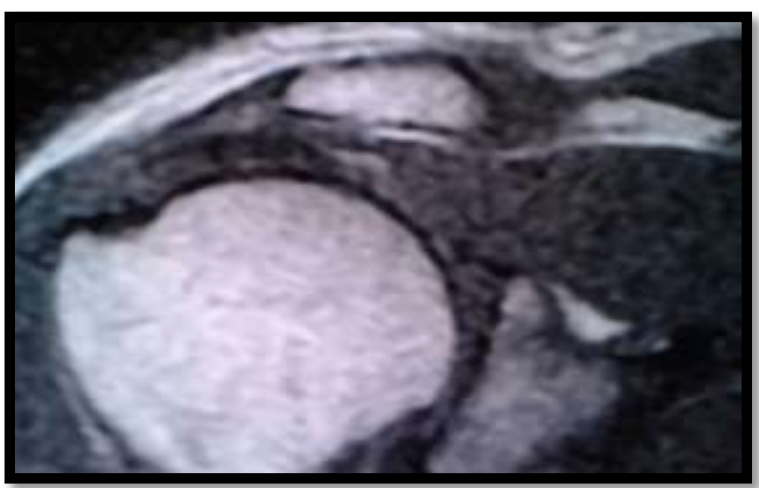

FIGURE 12: Coronal T2W image shows intra substance partial tear due to impingement

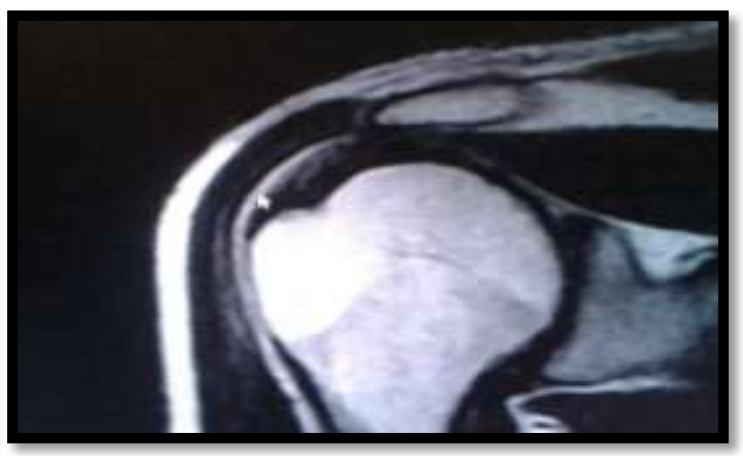

FIGURE 11: Coronal T2W image shows bursal Surface partial tear

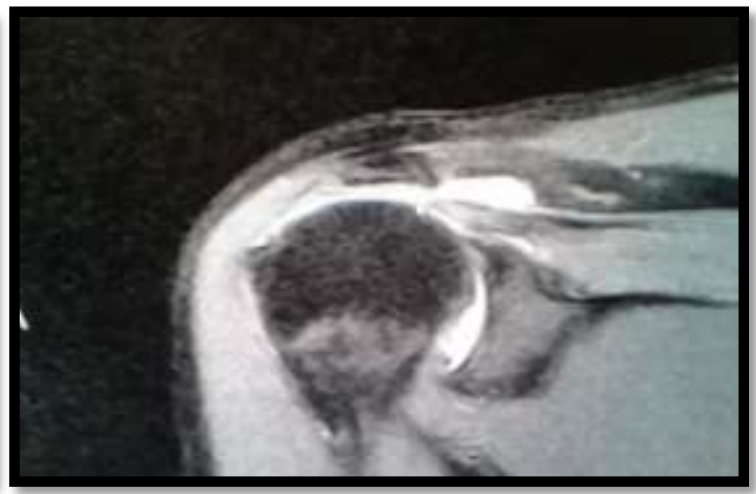

FIGURE 13: Coronal PD image shows complete supraspinatus tear with joint effusion \& fluid in subcoracoid bursa

Biceps pathology is frequently associated with chronic tears of the supraspinatus tendon. In subscapularis tendon ruptures, the biceps tendon may subluxate medially into the body of the subscapularis tendon or even completely luxate into the medial joint cavity $[24,25,26]$. As the biceps tendon runs through the so called rotator interval, the term "interval lesion" has been coined and refers specifically to lesions of that anterior portion of the rotator cuff that includes the rotator interval, which itself is bare of tendons (Fig 14 \& 15) . Lesions of the rotator interval therefore are frequently associated with tears of the coraco-humeral and superior glenohumeral ligaments, the so called rotator interval pulley of the biceps tendon $[2,42,43]$. The subscapularis tendon may also show tendinosis if there is the so called anterior or subcoracoid impingement $[2,27,28,29]$ 

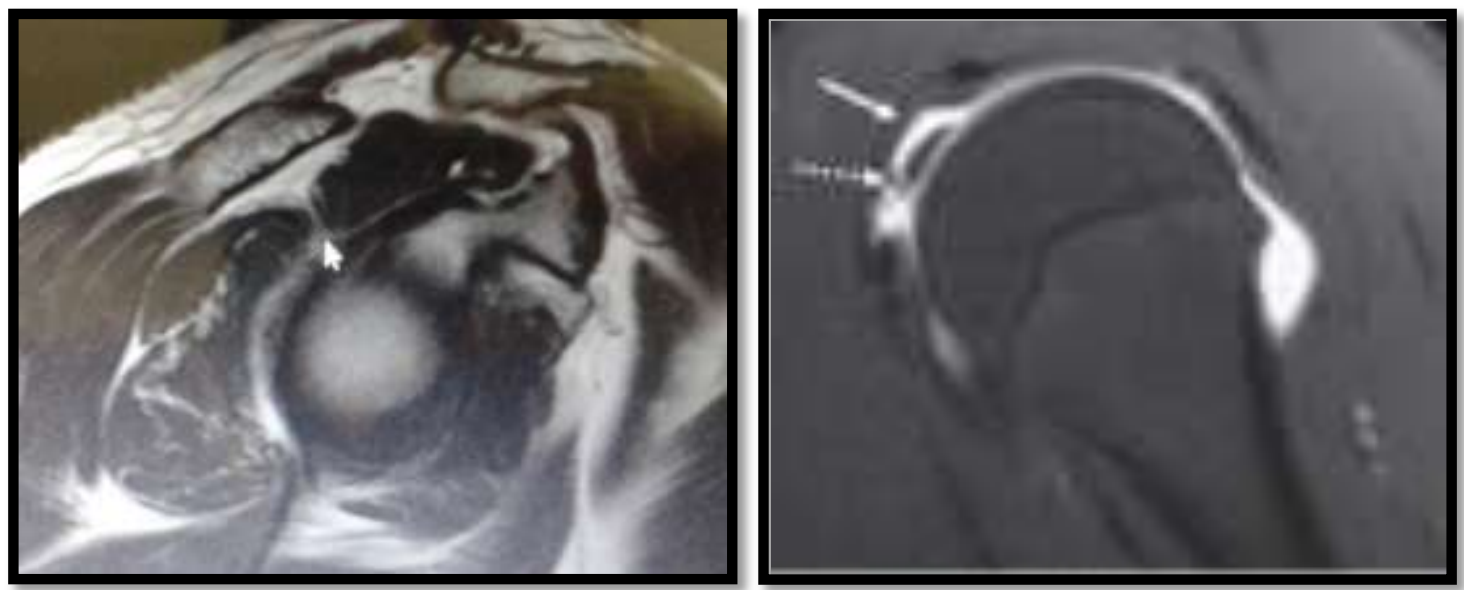

FIGURE 14 \& 15 : Sagital T2W MRI image shows rotator interval lesion

\section{Instability}

The shoulder joint, although featuring an extreme range of motion, exceeding the one of all other joints, under most circumstances is stable, due to the tendon reinforced joint capsule, several glenohumeral ligaments, various muscles, the glenoid labrum and least of all the osseous glenoid. An unstable shoulder joint can be habitual or occur after an acute trauma of the mentioned structures as after a dislocation, which possibly may lead to chronic instability. Instability can be anterior, posterior or multidirectional $[1,21,50]$. MR imaging in anterior instability can reveal a large number of abnormalities affecting the bone and labroligamentous tissue.

Hill-Sachs lesion: It is the most common injury associated with anterior glenohumeral instability. It consists of bony injury of the posterosuperior humeral head manifesting as cortical bony loss, impaction fracture or associated bone marrow edema in acute cases.(Fig 16)

Bankart lesion: It is the commonest labral injury, manifesting as tear of the anterior inferior labrum with associated periosteal tear $[1,38,39,40]$. It can be purely cartilaginous or may involve the bony glenoid rim (bony Bankart lesion). Bankart lesion is usually accompanied by Hill-Sachs lesion (Fig 17). Several other variants of Bankart lesion have been described, including the Perthes lesion, anterior labroligamentous periosteal sleeve avulsion (ALPSA) lesion, glenolabral articular disruption (GLAD) lesion.

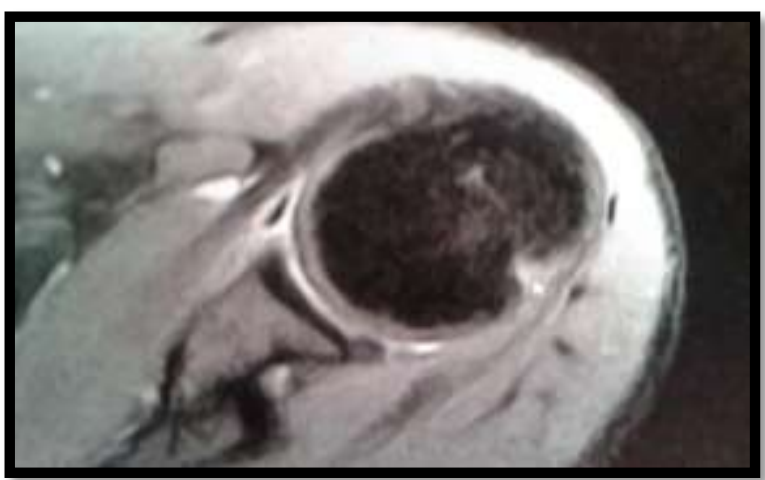

FIGURE 16: Axial PD image shows Hill sachs lesion

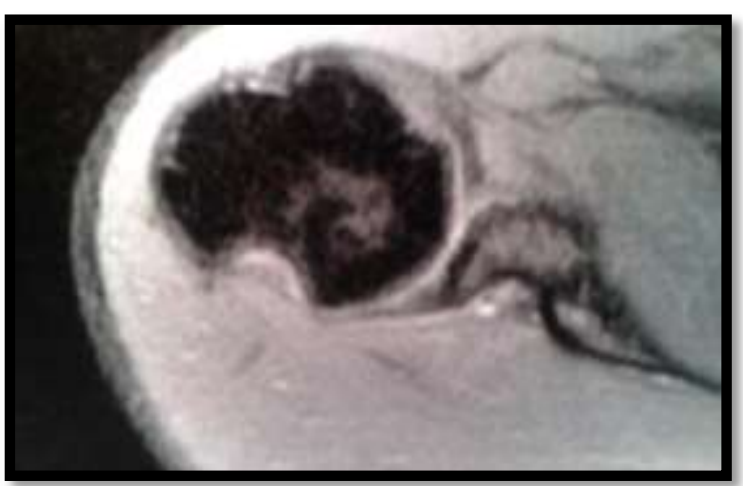

FIGURE 17: Axial PD image shows Hill sachs lesion along with soft tissue bankart

\section{Adhesive capsulitis (frozen shoulder)}

Adhesive capsulitis ( frozen shoulder) is a clinical syndrome of pain and restricted joint movement secondary to thickening and contraction of synovial sheath and joint capsule. It is most commonly seen in 40-60 years old female. It is associated with trauma, osteoarthritis or rheumatic disorder. MRI findings include, joint capsule and synovial thickening of $>4 \mathrm{~mm}$ at the level of Axillary recess is a useful crieteria to diagnose this condition. The normal inferior glenohumeral ligament measures $<4 \mathrm{~mm}$ and is best seen on coronal oblique images at the mid glenoid level. In adhesive capsulitis, the axillary recess may show thickening up to $1.3 \mathrm{~cm}$ or more. [41]( Fig 18 \& 19) 

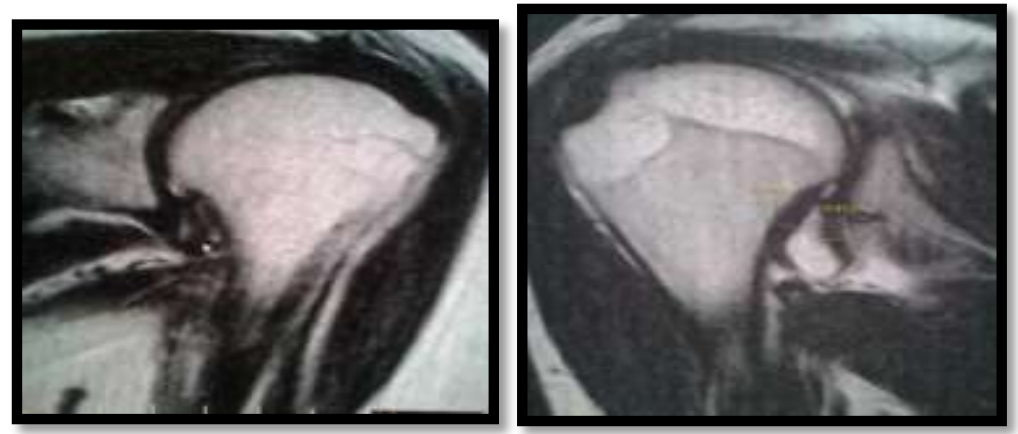

FIGURE 18 \& 19: Coronal oblique T2 image demonstrates a normal IGHL (arrow) measuring more than $4 \mathrm{~mm}$ in thickness

\section{Biceps tendinopathy}

The tendon of the long head of the biceps muscle (long bicipital tendon) has a complex course from its muscle belly to its insertion onto the supraglenoid tubercle/glenoid labrum. The Bicipital tendinopathy occurs in middle aged or older $[4,43]$.The biceps tendon often becomes attenuated or torn as a result of impingement syndrome The most reliable sign of a tear on imaging is the absence of the tendon in the bicipital groove .Retraction of the tendon and atrophy of the long head of biceps muscle may be seen . Medial dislocation commonly occurs as result of tears of the coracohumeral ligament which is the main stabilizer of the biceps tendon.
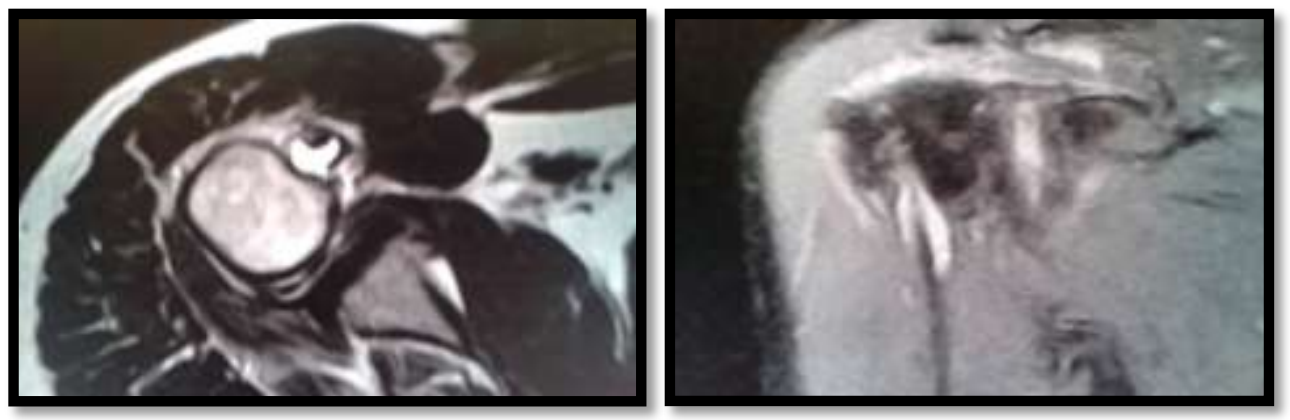

FIGURE 20 \& 21 : Coronal PD image shows fluid in bicipital groove \& along the biceps tendon sheath

\section{Material \& Method}

This prospective study was conducted in the Department of Radiodiagnosis, and NMC Sky Centre, L.L.R.M. Medical College, Meerut, in 81 patients with shoulder pain. A complete history of patients was taken and relevant clinical examination was performed in all the cases. All scans were done on Signa Contour (GE) MR Machine with super conducting magnet and field strength of 1.5 tesla using standard spine imaging techniques. T1- and T2-weighted images in the coronal, sagittal and axial planes were obtained in each patient.

\section{Observation And Result}

In a retrospective review, 81 consecutive patients ( 54 men, 27 women, average age 42.28 years) referred to our institution for diagnostic workup for shoulder complaints from August 2010 upto October 2012, analysed for the spectrum of diagnosed pathology. One or more diagnostic observations were made in each patient. All diagnoses are summarized in Table 1.

The findings can grossly be grouped in lesions of the rotator cuff (with its three portions the supraspinatus, the sabscapularis and the infraspinatus tendons plus the rotator-interval), lesions of the biceps tendon, lesions of the glenoid labrum and degenerative changes of the gleno-humeral and acromio- clavicular joint. Out of the 81 patients only 7 were without visible pathology. Rotator cuff tendinopathy accounts maximum in which Supraspinatus tendinopathy found in $67.65 \%$ cases (55 patients), subscapularis tendinopathy were in $9.9 \%$ ( 8 patients) cases ,infraspinatus tendinopathy were in $2.47 \%$ cases ( 2 patients) while rotator interval tear were in $3.70 \%$ cases ( 3 patients). Biceps tendinopathy were found in $12.35 \%$ cases (10 patients), bankart lesion in $8.61 \%$ ( 7 patients) \& hill sachs lesion in $11.11 \%$ ( 9 patients). There were $19.75 \%$ cases(16 patients) with acromioclavicular arthosis \& $15.99 \%$ (13 patients) with glenohumeral arthosis. Soft tissue pathology was abundant, being present in $22-55 \%$ of the cases, whereas occult fractures were seen in 
only $12.34 \%$ (10 patients). Subacromian -subdeltoid bursitis accounting 37.04\% (30 patients). There were $27.16 \%$ (22 patients) who were associated with joint effusion \& $7.40 \%$ ( 6 patients ) with synovial thickening.In our study $3.70 \%$ (3 patients) were found with adhesive capsulitis , 3.70\% (3 patients) with tuberculosis , 2.47\% cases ( 2 patients) with malignancy.

TABLE 1 : MRI findings: spectrum of pathologies

\begin{tabular}{|c|c|c|c|}
\hline SN & Diagnosis & No Of Patient & Percentage (\%) \\
\hline 1 & Supraspinatus tear & 35 & 43.21 \\
\hline 2 & Supraspinatus tendinosis & 20 & 24.69 \\
\hline 3 & Subscapularis tear/tendinosis & 08 & 09.90 \\
\hline 4 & Infraspinatus tear/tendinosis & 02 & 02.47 \\
\hline 5 & Biceps tendinosis tear/tendinosis & 10 & 12.35 \\
\hline 6 & Bankart lesion \& its variant & 07 & 08.61 \\
\hline 7 & Hill sachs lesion lesion & 09 & 11.11 \\
\hline 8 & Impingement & 05 & 06.15 \\
\hline 9 & Acromioclavicular arthosis & 16 & 19.75 \\
\hline 10 & Subacromian subdeltoid bursitis & 30 & 37.04 \\
\hline 11 & Adhesive capsulitis & 03 & 03.70 \\
\hline 12 & Rotator interval tear & 03 & 03.70 \\
\hline 13 & Joint effusion & 22 & 27.16 \\
\hline 14 & Bone bruise/ fracture & 12.35 \\
\hline 15 & Synovial thickening & 06 & 07.40 \\
\hline 16 & Tubercular & 03 & 03.69 \\
\hline 17 & Myositis & 01 & 01.23 \\
\hline 18 & Malignancy & 02 & 02.46 \\
\hline
\end{tabular}

IV. Discussion

Magnetic resonance imaging (MRI) of the shoulder joint has achieved wide acceptance as an imaging technique. This was initially due to the sensitivity and specificity of MRI for detection of rotator cuff pathologies. Evaluation of subtle humeral head changes, articular cartilage, synovial or labral pathology may require additional sequences \& intravenous or intra articular gadolinium. Early changes in articular cartilage may be more evident with fat suppressed T2 weighted fast spin echo sequences. MRI is extremely sensitive to alterations in the bone marrow and fluid in joint space that may represent pathology occult to plain radiography and bone scintigraphy of shoulder. MRI is a practical, well accepted and accurate non-invasive imaging technique in patients presenting with shoulder pain and is imaging modality of choice when clinical examination is suspect of shoulder disease and plain radiographs are normal or equivocal. The development of MR imaging afforded improved comprehensive visualization of the shoulder joint in a noninvasive manner. We evaluated MR imaging of the shoulder as become an important imaging modality for that joint. Excellent soft tissue contrast and multiplanar acquisition provide optimal assessment of muscle, tendons, hyaline and fibrous cartilage, joint capsules, fat, bursae and bone marrow

\section{Conclusion}

As in medicine, elaborate diagnosis obviously makes sense if there are means for adequate therapy and there is a good chance for better outcomes. In the field of musculoskeletal disease, MRI nowadays fulfils these criteria and in many cases it replaces other investigations.Thus, Shoulder MR is now considered the standard among the imaging methods for optimal depiction of almost all shoulder pathology.

\section{Bibilography}

[1] Manisha Jana :Magnetic resonance imaging in glenohumeral instability World J Radiol 2011 September 28; 3(9): 224-232

[2] Catherine N. Petchprapa, Luis S. Beltran, Laith M. Jazrawi, Young W. Kwon,James S. Babb1 and Michael P. Recht. The Rotator Interval: A Review of Anatomy, Function, and Normal and Abnormal MRI Appearance AJR 2010; 195:567-576

[3] Matthieu J. C. M. Rutten, Jan Spaargaren, Ton vaLoon, Maarten C. de Waal Malefijt, Lambertus A. L. M. Kiemeney, and Gerrit J. Jager1 Detection of rotator cuff tears: the value of MRI following ultrasound ,Eur Radiol. 2010 February; 20(2): 450-457

[4] Cree M. Gaskin, Mark W. Anderson, Asim Choudhri, David R. Diduch . Focal partial tears of the long head of the biceps brachii tendon at the entrance to the bicipital groove: MR imaging findings, surgical correlation, and clinical significance. October 2009, Volume 38, Issue 10, pp 959-965 
[5] Stoller DW, Wolfe EM, Li AE, Nottage WM, Tirman PFJ. The shoulder. In:Stoller DW.,editors.Magnetic resonance imaging in orthopedics and sports medicine. 3rd ed. Philadelphia, PA: Lippincott Williams and Wilkins; 2007.pp.1131-1462.

[6] Andreas Nidecker et al. Shoulder Joint Pathology - Improved Diagnosis By Magnetic Resonance Imaging (Mri):A Pictorial Essay And Review. Biblid 2008; 0370-8179, 136, 1-2, p. 50-61

[7] Gert Schippinger, David Bailey, Eugen G. McNally, Jenö Kiss and Andrew J. Carr Anatomy of the normal acromion investigated using MRILangenbeck's Archives of Surgery, 1997, Volume 382, Number 3, Pages 141-144

[8] Bachman, Melzer C, Heinrichs CM, Möhring B, Rominger MB. Diagnosis of rotator cuff lesions: comparison of US and MRI on 38 joint specimens ., Eur Radiol. 1997;7(2):192-7.

[9] Singson RD, Hoang T, Dan S, Friedman M. MR evaluation of rotator cuff pathology using T2-weighted fast spin-echo technique with and without fat suppression AJR Am J Roentgenol. 1996 May;166(5):1061-5.

[10] Della Sala SW, Bianchini G. Magnetic resonance in the study of the painful shoulder. Radiol Med. 1996 Apr;91(4):348-55.

[11] Uri DS, Kneeland JB, Dalinka MK Update in shoulder magnetic resonance imaging Magn Reson Q. 1995 Mar;11(1):21-44.

[12] Reinus WR, Shady KL, Mirowitz SA, Totty WG. MR diagnosis of rotator cuff tears of the shoulder: value of using T2-weighted fat-saturated images ,AJR Am J Roentgenol. 1995 Jun;164(6):1451-5

[13] Anthony Miniac, Paul A. Dowdy, i , Kevin R. Willits A. Dale Vellet, Resonance Imaging Evaluation of the Rotator Cuff Tendons in the Asymptomatic Shoulder Am J Sports Med March 1995vol. 23 no. 2 142-14

[14] Vahlensieck M, Resendes M, Genant HK, MRI of the shoulder, Bildgebung. 1992 Sep;59(3):123-32.

[15] Prendergast N, Rafii M. Magnetic resonance imaging of the shoulder joint. Curr Opin Radiol. 1992;4(6):70-6

[16] Farley TE, Neumann CH, Steinbach LS, Jahnke AJ, Petersen SS. Full-thickness tears of the rotator cuff of the shoulder: diagnosis with MR imaging AJR Am J Roentgenol. 1992 Feb;158(2):347-51.

[17] P A Kaplan, K C Bryans, J P Davick, M Otte, W W Stinson and R G Dussault MR imaging of the normal shoulder: variants and pitfalls August 1992 Radiology, 184,519-524.

[18] Neer CS. Impingement lesions. Clin Orthop 1998; 173:70-7.

[19] Morrison DS, Bigliani LU. The clinical significance of variations in acromial morphology. Orthop Trans 1987; 11:234.

[20] Morrison DS, Bigliani LU. Roentgenorgaphic analysis of acromial morphology and its relationship to rotator cuff tears. Orthop Trans 1987; 11:439.

[21] Jobe FW, Kvitne RS, Giangarra CE. Shoulder pain in the overhand or throwing athlete: the relationship of anterior instability and rotator cuff impingement. Orthop Rev 1989; 18:963-75.

[22] Gartsman GM, MilneJC. Articular surface partial- thickness rotator cuff tears. J Shoulder Elbow Surg 1995; 4:409-15..

[23] Post M, Silver R, Singh M. Rotator cuff tear: diagnosis and treatment. Clin Orthop 1983; 173:78-91.

[24] Deutsch A, Alchek DW, Veltri DM, et al. Traumatic tears of the sabscapularis tendon: clinical diagnosis, magnetic resonance imaging findings, and operative treatment. Am J Sports Med 1997; 25:13-22.

[25] Gerber C, Hersche O, Farron A. Isolated rupture of the sabscapularis tendon. J Bone Joint Surg Am 1996; 78:1015-23.

[26] Patten RM. Tears of the anterior portion of the rotator cuff (the sabscapularis tendon): MR imaging findings. Am J Roentgenol $1994 ; 162: 351-4$

[27] Dumontier C, Saulet A, Lenoble E, et al. Antero-medial impingement syndrome. J Shoulder Elbow Surg 1997; 6:198.

[28] Gerber C, Terrier F, Ganz R. The role of the coracoid process in the chronic impingement syndrome. J Bone Joint Surg Br 1985;67:703-8.

[29] Patte D. The subcoracoid impingement. Clin Orthop 1990; 254

[30] Worland RL, Lee D, Orozco CG, SozaRex F, Keenan J. Correlation of age, acromial morphology, and rotator cuff tear pathology diagnosed by ultrasound in asymptomatic patients. J South Orthop Assoc. 2003 Spring;12(1):23-6.

[31] B.C.H. de ZWART .M. H. W. Fings - dresen et al .Gender differences in upper extremity musculoskeltal complaints in the working population ,Int arch occup environ health 2001; 74:21-30

[32] Li XX, Schweitzer ME, Bifano JA, Lerman J, Manton GL, El-Noueam KI MR evaluation of subscapularis tears J Comput Assist Tomogr. 1999 Sep-Oct;23(5):713

[33] Hawkins R : Rotator cuff tear. presented at the orthopaedic symposium on rotator cuff tear, Antwerp , Belgium ,February 1989; 2425.

[34] Traugberg PD ,Goodwin TD ; shoulder MRI; Arthoscopic Correlation with emphasis on partial tear. J Comput Assist Tomogr 1992 ;16:129-133

[35] Zlatkin MB, Reicher MA, Kellerhouse LE, et al: The painful shoulder: MR imaging of the glenohumeral joint. J Comput Assist Tomogr $1988 ; 12: 995-1001$

[36] Snyder SJ: Rotator cuff: Introduction, evaluation, and imaging. In Snyder SJ (ed): Shoulder Arthroscopy, 2nd ed. Philadelphia, Lippincott Williams \& Wilkins 2003, p 184

[37] Fotiadou AN, Vlychou M, Papadopoulos P, Karataglis DS, Palladas P, Fezoulidis IV Ultrasonography of symptomatic rotator cuff tears compared with MR imaging and surgery. Eur J Radiol. 2008 Oct;68(1):174-9. Epub 2007 Dec 21

[38] Waldt S, Burkart A, Imhoff AB, Bruegel M, Rummeny EJ, Woertler K. Anterior shoulder instability: accuracy of MR arthrography in the classification of anteroinferior labroligamentous injuries. Radiology. 2005;237:578-583.

[39] Rowan KR, Keogh C, Andrews G, Cheong Y, Forster BB. Essentials of shoulder MR arthrography: a practical guide for the general radiologist. Clin Radiol 2004;59:327-334.

[40] Shankman S, Bencardino J, Beltran J. Glenohumeral instability: evaluation using MR arthrography of the shoulder. Skeletal Radiol. 1999;28:365-382

[41] Emig EW, Schweitzer ME, Karasick D, Lubowitz J . Adhesive capsulitis of the shoulder: MR diagnosis. AJR Am J Roentgenol. 1995 Jun;164(6):1457-9

[42] Chaipat L, Palmer WE. , Shoulder magnetic resonance imaging, Clin Sports Med. 2006 Jul;25(3):371-86, v.

[43] Erickson SJ, Fitzgerald SW, Quinn SF, Carrera GF, Black KP, Lawson TL, Long bicipital tendon of the shoulder: normal anatomy and pathologic findings on MR imaging. AJR Am J Roentgenol. 1992 May;158(5):1091-6.

[44] Erin E. O'Connor1, Larry B. Dixon, Terrance Peabody and Gregory Scott Stacy . MRI of Cystic and Soft-Tissue Masses of the Shoulder Joint . AJR July 2004 vol. 183 no. 139-47

[45] Zhu Q, Katsuya N , Normal anatomy and related pathological changes of shoulder on MRI, Zhonghua Wai Ke Za Zhi. 2000 Apr;38(4):259-62, 16

[46] Suh JS, Lee JD, Cho JH, Kim MJ, Han DY, Cho NH. MR imaging of tuberculous arthritis: Clinical and experimental studies. J Magn Reson Imaging 1996;6:185-9.

[47] Hong SH, Kim SM, Ahn JM, Chung HW, Shin MJ, Kang HS. Tuberculous versus pyogenic arthritis: MR imaging evaluation. Radiology 2001;218:848-53. 
[48] Thomas H. Berquist. MRI of the Musculoskeletal System ,2th edition. New York. raven press 1992; 579-607

[49] Walch G, Boileau P, Noel E, et al. Impingement of the deep surface of the supraspinatus tendon on the postero-superior glenoid rim: an arthroscopic study. J Shoulder Elbow Surg 1992; 1:238-45.

[50] Wirth MA, Lyons FR, Rockwood Jr C. Hypoplasie of the glenoid: a review of sixteen patients. J Bone Joint Surg 1993; 75A:117584.

[51] Weishaupt D, Zanetti M, Nyffeler RW, et al. Posterior glenoid rim deficiency in recurrent (atraumatic) posterior shoulder instability. Skeletal Radiology 2000; 29(4):204-10.

[52] Brewer BJ, Wubben RC, Carrera GF. Excessive retroversion of the glenoid cavity: a cause of non-traumatic posterior instability of the shoulder. J Bone Joint Surg 1986; 68A:724-31.

[53] Ferrari DA. Capsular ligaments of the shoulder. Anatomical and functional study of the anterior capsule (case report). Am J Sport Med 1990; 18:20-4.

[54] Bigliani LU, Pollock RG, Soslowsky LJ, et al. Tensile properties of the inferior glenohumeral ligament. J Ortho Res 1992; 10:18797.

[55] Sanders T, Morrison W, Miller M. Imaging techniques for the evaluation of glenohumeral instability. Am J Sports Med 2000; 28(3):414-34.

[56] Schweitzer ME. MR arthrography of the labral- ligamentous complex of the shoulder. Radiology 1994; 190:641-3.

[57] Turkel SJ, Panio MW, Marshall JL, et al. Stabilizing mechanism preventing anterior dislocation of the glenohumeral joint. J Bone Joint. Surg 1998: 63A:1208-1

[58] P.D. Chudgar: Spectrum Of MRI Findings In Musculoskeletal Tuberculosis: Pictoral Essay. The Internet Journal of Radiology. 2008 Volume 8 Number 2. 